\title{
Full Genome Sequences of Zebra-Borne Equine Herpesvirus Type 1 Isolated from Zebra, Onager and Thomson's Gazelle
}

\author{
Xiaoqin GUO $^{1)}$, Satoko IZUME ${ }^{1)}$, Ayaka OKADA ${ }^{1)}$, Kenji OHYA ${ }^{1,2)}$, Takashi KIMURA ${ }^{3)}$ and Hideto FUKUSHI ${ }^{1,2) *}$ \\ 1) Department of Applied Veterinary Sciences, United Graduate School of Veterinary Sciences, Gifu University, 1-1 Yanagido, Gifu \\ 501-1193, Japan \\ 2) Laboratory of Veterinary Microbiology, Faculty of Applied Biological Sciences, Gifu University, 1-1 Yanagido, Gifu 501-1193, Japan \\ ${ }^{3)}$ Laboratory of Comparative Pathology, Graduate School of Veterinary Medicine, Hokkaido University, Kita 18, Nishi 9, Kita-ku, \\ Sapporo 060-0818, Japan
}

(Received 6 April 2014/Accepted 23 May 2014/Published online in J-STAGE 11 June 2014)

ABSTRACT. A strain of equine herpesvirus type 1 (EHV-1) was isolated from zebra. This strain, called "zebra-borne EHV-1", was also isolated from an onager and a gazelle in zoological gardens in U.S.A. The full genome sequences of the 3 strains were determined. They shared 99\% identities with each other, while they shared $98 \%$ and $95 \%$ identities with the horse derived EHV-1 and equine herpesvirus type 9 , respectively. Sequence data indicated that the EHV-1 isolated from a polar bear in Germany is one of the zebra-borne EHV-1 and not a recombinant virus. These results indicated that zebra-borne EHV-1 is a subtype of EHV-1.

KEY WORDS: equine herpesvirus, genome sequence, zebra

doi: 10.1292/jvms.14-0183; J. Vet. Med. Sci. 76(9): 1309-1312, 2014

Equine herpesvirus type 1 (EHV-1; genus Varicellovirus, subfamily alphaherpesvirinae) has been isolated from zebras and other zoo animals $[1,8,12,16,21]$. Especially, the 1 isolated from zebras has been focused as an emerging agent in zoo animals. The EHV-1 associated with zebras has been called as zebra-borne EHV-1 [1]. Zebra-borne EHV-1 has been isolated from wild equids kept in zoological gardens. EHV-1 T-529 was isolated from a Persian onager (Equus hemionus onager) fetus in February 1984 [16]. Associated with this case, a 9-month-old male plains zebra (Equus quagga burchelli), which was kept in a pen adjacent to the onagers, developed illness a week after the onager abortion. In October 1984, a Grevy's zebra (Equus grevyi) at the Lincoln Park Zoo in Chicago aborted a fetus from which EHV-1 T-616 was isolated [21]. Systemic infection by EHV-1 in a Grevy's zebra stallion was also reported in 1998 [2]. EHV-1 has been isolated from non-equine species including camels, antelopes, cattle, fallow deer, alpacas, llamas and Thomson's gazelle (Eudorcas thomsoni) from which EHV-1 94-137 was isolated [12]. A polar bear (Ursus maritimus), named Jerka, kept in a zoo in Berlin died from acute encephalitis [8], and a strain of zebra-borne EHV-1 was subsequently isolated from it. The nucleotide sequence analysis of the Pol gene (ORF30 in EHV-1 gene nomenclature [18], a homologue of herpes simplex virus 1 (HSV-1) UL30) in this virus indicated that the virus was a recombinant virus between EHV-1

*Correspondence to: Fukushi, H., Laboratory of Veterinary Microbiology, Faculty of Applied Biological Sciences, Gifu University, 1-1 Yanagido, Gifu 501-1193, Japan.

e-mail: hfukushi@gifu-u.ac.jp

(C)2014 The Japanese Society of Veterinary Science

This is an open-access article distributed under the terms of the Creative Commons Attribution Non-Commercial No Derivatives (by-nc-nd) License $<$ http://creativecommons.org/licenses/by-nc-nd/3.0/>. and equine herpesvirus type 9 (EHV-9), which was isolated from an epizootic encephalitis of Thomson's gazelles kept in a zoo in Japan $[4,5]$. A similar zebra-borne EHV-1 was detected in an Indian rhinoceros (Rhinoceros unicornis) affected by severe neurological disease [1]. All of these cases were reported to be associated with zebras (E. q. burchelli and $E$. gravyi) kept at places close to the affected animals.

In the present study, we determined the full genome sequences of 3 zebra-borne EHV-1s isolated from a zebra, an onager and a gazelle (strains T-616, T-529 and 94-137, respectively). We have reported the phylogenic relatedness among the 3 viruses based on the nucleotide sequences of the genes for glycoproteins B (ORF33, a homologue of HSV-1 UL31), G (ORF70, a homologue of HSV-1 US4), I (ORF73, a homologue of HSV-1 US7) and E (ORF74, a homologue of HSV-1 US8), and teguments including ORF8 (a homologue of HSV-1 UL51), ORF15 (a homologue of HSV-1 UL45) and ORF68 (a homologue of HSV-1 US2) [6, 10]. Our results in the present study indicate that the zebra-borne EHV-1 forms an independent group of viruses phylogenetically and that the zebra-borne EHV-1 suspected to have killed Jerka is not a recombinant virus.

T-529 and T-616 were kindly provided by Dr. G. P. Allen (University of Kentucky, U.S.A.), and 94-137 was kindly provided by Dr. Kennedy (University of Tennessee, U.S.A.). The 3 strains of zebra-borne EHV-1 were cultured in fetal equine kidney (FEK) cells. After the virus stocks were obtained, the stocks were passaged several times for viral genomic DNA extraction. The viral genome DNA was extracted from the cells [20]. Genome sequences of the 3 strains of zebra-borne EHV-1 (T-616, T-529 and 94-137) were read by the next generation sequencer GS Junior (Roche, New York, NY, U.S.A.) according to the manufacturer's protocol. The complete genomes were assembled by reference sequence mapping with Bowtie 2 [13] and editing with Consed [7] and 


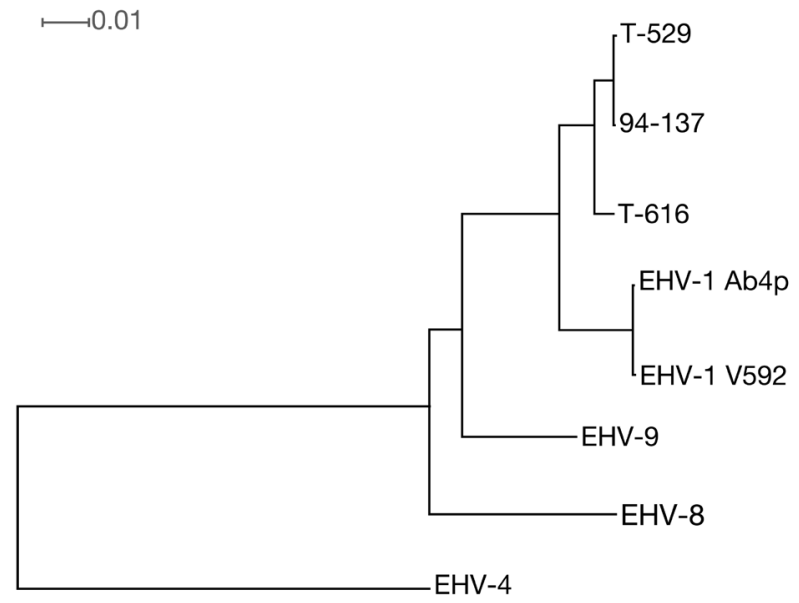

Fig. 1. Neighbor-joining phylogenic tree based on the genome sequences of 3 zebra-borne EHV-1 (T-616: KF644573; T-529: KF644580; 94-137: KF644575), 2 horse strains of EHV-1 (Ab4p:AY665713; V592:AY464052) [16, 17], EHV-8 (JQ343919) [14], EHV-9 (AP010838) [5] and EHV-4 (AF030027) [19]. All node has $100 \%$ bootstrap value. The tree was constructed by SplitsTree [9]. The scale bar is given by average number of mutations per site.

SnapGene (GSL Biotech LLC, Chicago, IL, U.S.A.).

The T-616 DNA sequencing indicated to include 2 viruses, designated T-616 substrains 1 and 2, with lengths of $150,562 \mathrm{bp}$ and $148,847 \mathrm{bp}$, respectively (accession nos. KF644573 and KF644574, respectively). The lengths of the T-529 and 94-137 genomes were 147,963 bp and 149,457 bp, respectively (accession nos. KF644580 and KF644575, respectively). Multiple alignment was examined by MAFTT [11]. The 3 genomes shared $99 \%$ identities with each other and shared $98 \%$ and $95 \%$ identities with the horse derived EHV-1 and EHV-9. Phylogenic analyses based on the whole genome sequences indicated that T-529 and 94-137 are closely related to each other and distantly related to T-616 (Fig. 1).

Single nucleotide polymorphisms (SNPs) and insertions and deletions (indels) of nucleotides were detected with whole genome sequence comparison. The differences among the genome lengths are caused by large deletions, variation of tandem repeat sequences including repeats in ORF24 (a homologue of HSV-1 UL36) and ORF71 (a homologue of HSV-1 US5), ORF64 (a homologue of HSV-1 ICP4 gene) downstream and an intergenic region between ORF62 (a homologue of HSV-1 UL1) and ORF63 (a homologue of HSV-1 ICP0 gene).

Two large deletions were observed in T-616 substrain 2 and T-529. A 1,714 bps deletion is found in T-616 substrain 2 , corresponding to nucleotides 128,715 to 130,428 in T-616 substrain 1 (Fig. 2A). This deletion caused amino acid sequence mutation with truncation of ORF70 and the lack of ORF71 in T-616 substrain 2 (Fig. 2 A and 2B). The 2 substrains of T-616 were cloned by plaque purification, and the difference was confirmed by PCR (Fig. 2C). Although DNA

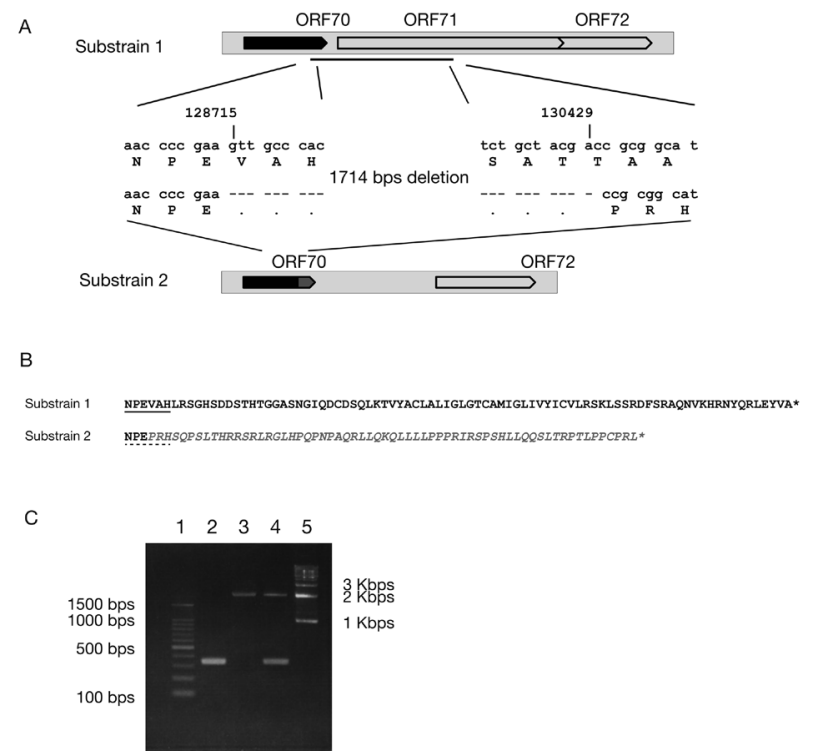

Fig. 2. (A) Nucleotide deletion from the tail part of ORF70 to the head part of ORF71. The arrow in black indicates the original ORF70. The other arrow in dark grey indicates the truncated tail part of ORF70 caused by deletion. (B) Amino acid sequence alignments of the tail part of ORF70 in Substrains 1 and 2. The amino acid sequences with underline indicate the corresponding sequences shown in the panel $\mathrm{A}$. The amino acid sequence in italic grey indicates the truncated tail of ORF70 caused by the deletion. The asterisks $(*)$ indicate the placement of stop codon in the original nucleotide sequence. (C) PCR results to confirm the presence of 2 viruses in T-616. PCR primers used were as follows: Zebra_71-F 5'-ccaacgtaccatcaagtgcggta-3' and Zebra_71-R $5^{\prime}$-cgetggtactctcgtaggttgac-3'. PCR was examined by using PrimeSTAR Max Premix (TaKaRa Bio, Otsu, Japan) with amplification program as follows: the primary hold at $95^{\circ} \mathrm{C}$ for $4 \mathrm{~min}, 30$ cycles of $98^{\circ} \mathrm{C} 10 \mathrm{sec}, 55^{\circ} \mathrm{C} 15 \mathrm{sec}$ and $72^{\circ} \mathrm{C} 45 \mathrm{sec}$. Lanes were 100 bp ladder marker (1), T-616 substrain 2 (2), T-616 substrain 1 (3), the original seed stock of T-616 (4) and 1 kbp ladder marker (5). Expected sizes are 344 bps for T-616 substrain 2 and 2,058 bps for T-616 substrain 1.

fingerprints were shown in the report by Wolff et al. [21], it is unclear that the original isolate from the zebra consisted of 2 substrains or not. On the other hand, the genome of T-529 lacks 1,611 bp region that contains ORF1 and ORF2. Therefore, T-529 does not possess proteins encoded by ORF1 and ORF2.

T-529 and 94-137, which are phylogenetically related, were isolated from zoo animals (an onager and a gazelle, respectively) that were kept close to plains zebras (E. q. burchelli), while T-616 was isolated from a Grevy's zebra (E. grevyi). The phylogenic relatedness among these zebraborne viruses seems to reflect the phylogenetic relatedness among the host zebra species [3].

We reported that the present 3 zebra-borne EHV-1s caused severe neurological disease in hamster [10]. Nugent et al. indicated the EHV-1 causing equine herpesvirus myeloencephalopathy should have the neuropathogenic marker of D752 in ORF30 [17]. The present 3 zebra-borne EHV-1 
Table 1. Amino acid differences and synonymous differences among zebra borne EHV-1

\begin{tabular}{|c|c|c|c|c|c|c|c|c|c|c|c|c|c|}
\hline \multirow{3}{*}{$\begin{array}{c}\text { Gene } \\
\begin{array}{c}\text { Covered } \\
\text { position }\end{array} \\
\begin{array}{c}\text { Amino acid } \\
\text { position }\end{array}\end{array}$} & \multirow{3}{*}{$\begin{array}{c}\begin{array}{c}\text { ORF10 } \\
\text { com- } \\
\text { plete } \\
\text { gene }\end{array} \\
19\end{array}$} & \multirow{2}{*}{\multicolumn{2}{|c|}{$\begin{array}{l}\text { ORF15 } \\
1 \text { to } 218\end{array}$}} & \multicolumn{3}{|c|}{ ORF16 } & \multicolumn{4}{|c|}{ ORF30 } & \multirow{3}{*}{$\begin{array}{c}\text { ORF33 } \\
\begin{array}{c}500 \text { to } \\
878\end{array} \\
516\end{array}$} & \multicolumn{2}{|c|}{ ORF67 } \\
\hline & & & & & smplete ge & & & $675 t$ & to 954 & & & 85 to & o 198 \\
\hline & & 216 & 217 & 107 & 150 & 450 & 739 & 754 & 873 & 939 & & 89 & 109 \\
\hline T-529 & $L(T T G)$ & $\mathrm{P}(\mathrm{CCG})$ & F (TTT) & E (GAG) & $\mathrm{R}$ (CGA) & $\mathrm{A}(\mathrm{GCC})$ & L (CTT) & S (TCG) & F (TTC) & $\mathrm{K}$ (AAA) & $\mathrm{N}(\mathrm{AAT})$ & $\mathrm{A}(\mathrm{GCA})$ & V (GTT) \\
\hline 94-137 & $\mathrm{L}(\mathrm{CTG})$ & $\mathrm{P}(\mathrm{CCG})$ & F (TTT) & $\mathrm{E}(\mathrm{GAG})$ & $\mathrm{R}$ (CGA) & A (GCC) & $\mathrm{L}(\mathrm{CTT})$ & S (TCG) & F (TTC) & K (AAA) & N (AAT) & $\mathrm{A}(\mathrm{GCA})$ & V (GTT) \\
\hline T-616 & $\mathrm{L}(\mathrm{CTG})$ & $\mathrm{P}(\mathrm{CCG})$ & F (TTT) & $\mathrm{E}(\mathrm{GAG})$ & $\mathrm{R}$ (CGA) & $A(G C A)$ & $L(C T C)$ & $S(T C A)$ & $F(T T T)$ & $K(A A G)$ & $\mathrm{N}(\mathrm{AAT})$ & $\mathrm{A}(\mathrm{GCA})$ & $V(G T C)$ \\
\hline $\begin{array}{l}\text { Polar Bear } \\
\text { Jerka }\end{array}$ & L (CTG) & $P(C C A)$ & $I(A T T)$ & $Q(C A G)$ & $L(C T A)$ & A (GCC) & $\mathrm{L}(\mathrm{CTC})$ & $\mathrm{S}$ (TCG) & $F(T T T)$ & $\mathrm{K}$ (AAA) & $D(G A T)$ & $A(G C C)$ & $\mathrm{V}(\mathrm{GTT})$ \\
\hline
\end{tabular}

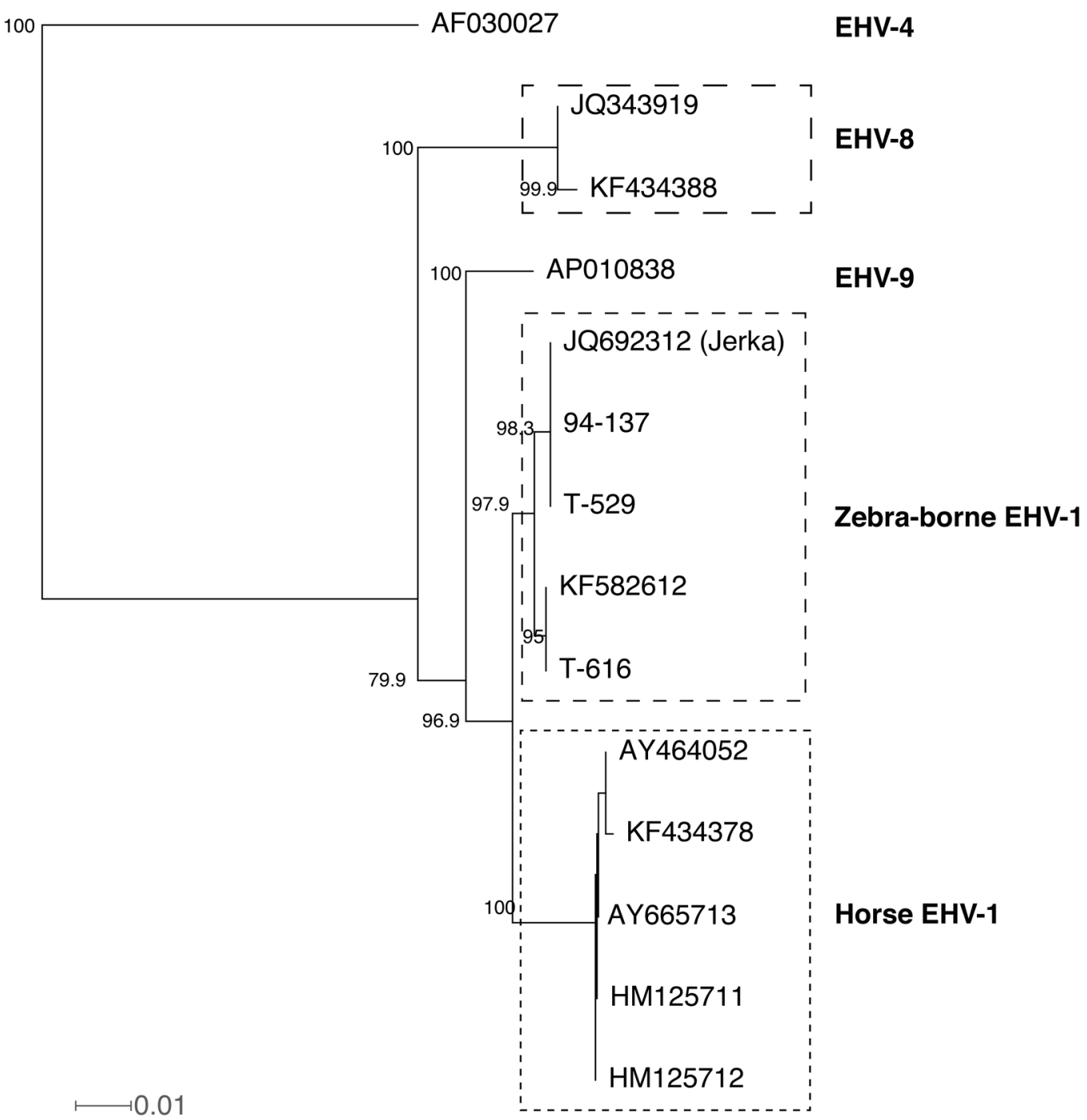

Fig. 3. Neighbor-joining phylogenic tree based on nucleotide sequences corresponding to 2023 to 2832 of ORF30. Labels in the tree are accession numbers. All sequences were obtained from GenBank. Numbers are bootstrap values greater than $70 \%$. The tree was constructed by SplitsTree [9]. The scale bar is given by average number of mutations per site. 
strains have the neuropathogenic marker D752 in ORF30, indicating that the 3 strains might be neuropathogenic.

Greenwood et al. [8] reported nucleotide sequences of ORF10 (a homologue of HSV-1 UL49.5), ORF15 (a homologue of HSV-1 UL45), ORF16 (a homologue of HSV-1 UL44), ORF30, ORF33 (a homologue of HSV-1 UL27) and ORF67 (also called IR6) of the zebra borne EHV-1 isolated from Jerka. The corresponding amino acid sequences of ORF10, ORF30 and ORF67 in the present 3 zebra-borne EHV-1s are identical to those of the zebra-borne EHV-1 isolated from Jerka, although 1 to 4 base differences were found among them (Table 1). Amino acid sequence differences were found 1 in ORF15, 2 in ORF16 and 1 in ORF33 between the zebra-borne EHV-1 isolated from Jerka and the present 3 zebra-borne EHV-1s. These data indicated that the zebra borne-EHV-1 isolated from Jerka should be regarded as an almost identical virus to the present 3 zebra-borne EHV1s. Greenwood et al. [8] discussed that ORF30 of the virus isolated from Jerka was a recombinant gene between those of EHV-1 and EHV-9, with the 5'-portion of the amplicon being EHV1-like, the middle being EHV9-like and the last 110 bp again being EHV1-like based on computer analysis of amplicon. Although we evaluated the recombination possibility of this area using the same data set in the reference 8 , we did not find any evidences of recombination in this area, where they insisted that the recombination occurred, by using 2 programs of SplitsTree [9] and TOPALi [15]. Phylogenic tree prepared by SplitsTree based on ORF30 nucleotide sequences is shown in Fig. 3. If the recombination was scientifically supported, the recombination should be detected using any algorithms for finding recombination. Therefore, it is unable to conclude that the zebra-borne EHV-1 isolated from Jerka was a recombinant virus. The 3 zebra-borne EHV-1 viruses analyzed in the present study and the virus isolated from Jerka might be a subtype of EHV-1 that was derived from the same ancestor virus of EHV-1.

In recent years, fatal encephalitis induced by the zebra borne equine herpesvirus has been reported frequently $[1,8]$. The risk of zebra-borne EHV-1 infection in the zoos cannot be ignored.

\section{REFERENCES}

1. Abdelgawad, A., Azab, W., Damiani, A. D., Baumgartner, K., Will, H., Osterrieder, N. and Greenwood, A. D. 2014. Zebraborne equine herpesvirus type $1(\mathrm{EHV}-1)$ infection in non-African captive mammals. Vet. Microbiol. 169: 102-106. [Medline] [CrossRef]

2. Blunden, A. S., Smith, K. C., Whitewell, K. E. and Dun, K. A. 1998. Systemic infection by equid herpesvirus-1 in a Grevy's zebra stallion (Equus grevyi) with particular reference to genital pathology. J. Comp. Pathol. 119: 485-493. [Medline] [CrossRef]

3. Côté, O., Viel, L. and Bienzle, D. 2013. Phylogenetic relationships among Perissodactyla: Secretoglobin 1A1 gene duplication and triplication in the Equidae family. Mol. Phylogenet. Evol. 69: 430-436. [Medline] [CrossRef]

4. Fukushi, H., Tomita, T., Taniguchi, A., Ochiai, Y., Kirisawa, R., Matsumura, T., Yanai, T., Masegi, T., Yamaguchi, T. and Hirai, K. 1997. Gazelle herpesvirus 1: a new neurotropic herpesvirus immunologically related to equine herpesvirus 1 . Virology 227:
34-44. [Medline] [CrossRef]

5. Fukushi, H., Yamaguchi, T. and Yamada, S. 2012. Complete genome sequence of equine herpesvirus type 9. J. Virol. 86: 13822. [Medline] [CrossRef]

6. Ghanem, Y. M., Fukushi, H., Ibrahim, E. S. M., Ohya, K., Yamaguchi, T. and Kennedy, M. 2008. Molecular phylogeny of equine herpesvirus 1 isolates from onager, zebra and Thomson's gazelle. Arch. Virol. 153: 2297-2302. [Medline] [CrossRef]

7. Gordon, D. and Green, P. 2013. Consed: a graphical editor for next-generation sequencing. Bioinformatics 29: 2936-2937. [Medline] [CrossRef]

8. Greenwood, A. D., Tsangaras, K., Ho, S. Y. W., Szentiks, C. A., Nikolin, V. M., Ma, G., Damiani, A., East, M. L., Lawrenz, A., Hofer, H. and Osterrieder, N. 2012. A potentially fatal mix of herpes in zoos. Curr. Biol. 22: 1727-1731. [Medline] [CrossRef]

9. Huson, D. H. and Bryant, D. 2006. Application of phylogenetic networks in evolutionary studies. Mol. Biol. Evol. 23: 254-267. [Medline] [CrossRef]

10. Ibrahim, E. S., Kinoh, M., Matsumura, T., Kennedy, M., Allen, G. P., Yamaguchi, T. and Fukushi, H. 2007. Genetic relatedness and pathogenicity of equine herpesvirus 1 isolated from onager, zebra and gazelle. Arch. Virol. 152: 245-255. [Medline] [CrossRef]

11. Katoh, K. and Standley, D. M. 2013. MAFFT Multiple sequence alignment software version 7: Improvements in performance and usability. Mol. Biol. Evol. 30: 772-780. [Medline] [CrossRef]

12. Kennedy, M. A., Ramsay, E., Diderrich, V., Richman, L., Allen, G. P. and Potgieter, L. N. D. 1996. Encephalitis associated with a variant of equine herpesvirus 1 in a Thomson's gazelle (Gazella thomsoni). J. Zoo Wildl. Med. 27: 533-538.

13. Langmead, B. and Salzberg, S. L. 2012. Fast gapped-read alignment with Bowtie 2. Nat. Methods 9: 357-359. [Medline] [CrossRef]

14. Liu, C., Guo, W., Lu, G., Xiang, W. and Wang, X. 2012. Complete genomic sequence of an equine herpesvirus type $8 \mathrm{Wh}$ strain isolated from China. J. Virol. 86: 5407. [Medline] [CrossRef]

15. Milne, I., Wright, F., Rowe, G., Marshal, D. F., Husmeier, D. and McGuire, G. 2004. TOPALi: Software for Automatic Identification of Recombinant Sequences within DNA Multiple Alignments. Bioinformatics 20: 1806-1807. [Medline] [CrossRef]

16. Montali, R. J., Allen, G. P., Bryans, J. T., Philips, L. G. and Bush, M. 1985. Equine herpesvirus type 1 abortion in an onager and suspected herpesvirus myelitis in a zebra. JAVMA 187: 1248-1249. [Medline]

17. Nugent, J., Birch-Machin, I., Smith, K. C., Mumford, J. A., Swann, Z., Newton, J. R., Bowden, R. J., Allen, G. P. and DavisPoynter, N. 2006. Analysis of equid herpesvirus 1 strain variation reveals a point mutation of the DNA polymerase strongly associated with neuropathogenic versus non- neuropathogenic disease outbreaks. J. Virol. 80: 4047-4060. [Medline] [CrossRef]

18. Telford, E. A., Watson, M. S., McBride, K. and Davison, A. J. 1992. The DNA sequence of equine herpesvirus-1. Virology 189: 304-316. [Medline] [CrossRef]

19. Telford, E. A., Watson, M. S., Perry, J., Cullinane, A. A. and Davison, A. J. 1998. The DNA sequence of equine herpesvirus-4. J. Gen. Virol. 79: 1197-1203. [Medline]

20. Volkening, J. D. and Spatz, S. J. 2009. Purification of DNA from the cell-associated herpesvirus Marek's disease virus for 454 pyrosequencing using micrococcal nuclease digestion and polyethylene glycol precipitation. J. Virol. Methods 157: 55-61. [Medline] [CrossRef]

21. Wolff, P. L., Meehan, T. P., Basgall, E. J., Allen, G. P. and Sundberg, J. P. 1986. Abortion and perinatal foal mortality associated with equine herpesvirus type 1 in a herd of Grevy's zebra. $J$. Am. Vet. Med. Assoc. 189: 1185-1186. [Medline] 